\title{
Risk factors affecting the mortality of HIV- infected patients with pulmonary tuberculosis in the CART era: a retrospective cohort study in China
}

Yong-Jia Ji ${ }^{1 \dagger}$, Pei-Pei Liang ${ }^{1 \dagger}$, Jia-Yin Shen ${ }^{1 \dagger}$, Jian-Jun Sun ${ }^{1}$, Jun-Yang Yang ${ }^{1}$, Jun Chen ${ }^{1}$, Tang-Kai Qi ${ }^{1}$, Zhen-Yan Wang ${ }^{1}$, Wei Song ${ }^{1}$, Yang Tang ${ }^{1}$, Li Liu' ${ }^{1}$, Ren-Fang Zhang ${ }^{1}$, Yin-Zhong Shen ${ }^{1}$ and Hong-Zhou Lu ${ }^{1,2,3^{*}}$

\begin{abstract}
Background: Tuberculosis infection still places a great burden on HIV-infected individuals in China and other developing countries. Knowledge of the survival of HIV-infected patients with pulmonary tuberculosis (PTB) would provide important insights for the clinical management of this population, which remains to be well described in current China.

Methods: HIV-infected patients with PTB admitted to Shanghai Public Health Clinical Center from January 2011 to December 2015 were retrospectively enrolled. In this cohort, the survival prognosis was estimated by the KaplanMeier method, while univariate and multivariate Cox proportional hazards models were used to determine the risk factors affecting mortality.

Results: After reviewing 4914 admitted patients with HIV infection, 359 PTB cases were identified. At the time of PTB diagnosis, the patients' median CD4 ${ }^{+} \mathrm{T}$ cell count was $51 / \mathrm{mm}^{3}$ (IQR: 23-116), and 27.30\% of patients (98/359) were on combination antiretroviral therapy (CART). For the 333 cases included in the survival analysis, the overall mortality was 15.92\% (53/333) during a median 27-month follow-up. The risk factors, including age older than 60 years (HR: 3.18; 95\% Cl: 1.66-6.10), complication with bacterial pneumonia (HR: 2.64; 95\% Cl: 1.30-5.35), diagnosis delay (HR: 2.60; 95\% Cl: 1. 42-4.78), CD4 ${ }^{+}$T cell count less than 50/ $\mathrm{mm}^{3}$ (HR: 2.38; 95\% Cl: 1.27-4.43) and pulmonary atelectasis (HR: 2.20; 95\% Cl: 1.05-4.60), might independently contribute to poor survival. Among patients without CART before anti-TB treatment, the later initiation of CART (more than 8 weeks after starting anti-TB treatment) was found to increase the mortality rate (OR: 4.33; 95\% Cl: 1.22-15.36), while the initiation of CART within 4-8 weeks after starting anti-TB treatment was associated with the fewest deaths (0/14).

(Continued on next page)
\end{abstract}

\footnotetext{
* Correspondence: luhongzhou@fudan.edu.cn

${ }^{\dagger}$ Equal contributors

'Department of Infectious Disease, Shanghai Public Health Clinical Center,

Fudan University, No. 2901 Cao Lang Rd, Jinshan District, Shanghai 201508,

China

${ }^{2}$ Department of Infectious Disease, Huashan Hospital Affiliated to Fudan

University, Shanghai 200040, China

Full list of author information is available at the end of the article
} 


\begin{abstract}
(Continued from previous page)
Conclusions: The subjects in this study conducted in the CART era were still characterized by depressed immunological competence and low rates of CART administration, revealing possible intervention targets for preventing TB reactivation in HIV-infected individuals under current circumstances. Furthermore, our study indicated that the timely diagnosis of PTB, prevention of secondary bacterial pneumonia by prophylactic management and optimization of the timing of cART initiation could have significant impacts on decreasing mortality among HIV/PTB co-infected populations. These findings deserve further prospective investigations to optimize the management of HIV/PTB-co-infected patients.
\end{abstract}

Trial registration: NCT01344148, Registered September 14, 2010.

Keywords: HIV infections, Acquired immunodeficiency syndrome, Pulmonary tuberculosis, Survival analysis

\section{Multilingual abstracts}

Please see Additional file 1 for translations of the abstract into the five official working languages of the United Nations.

\section{Background}

Globally, tuberculosis (TB) and human immunodeficiency virus (HIV) co-infection is a major public health problem. It has been estimated that more than one-third of individuals with HIV infection develop active TB infection [1]. Additionally, in 2015, the World Health Organization (WHO) reported that approximately $11 \%$ of the 10.4 million incident cases of TB infection worldwide occurred in patients co-infected with HIV [2]. Particularly in developing countries with limited medical resources, TB is one of the most common opportunistic infections in acquired immunodeficiency syndrome (AIDS) patients [3-5].

Both TB and HIV drastically affect the host's immune system because they can evade immune surveillance and clearance, although the mechanism is not fully understood [6]. In individuals co-infected with HIV and TB, the two pathogens potentiate each other and accelerate the deterioration of immunological functions, resulting in poor outcomes [6]. Compared with that in non-HIVinfected populations, the risk of latent TB activation increases 20-fold in HIV-infected patients [7]. TB infection has also been reported to exacerbate HIV replication [8]. With TB infection, the cytokines induced by immune responses could enhance the replication of HIV and accelerate AIDS progression [9]. For this reason, TB infection has been one of the most common causes of death in HIV-infected patients, accounting for $26 \%$ of AIDSrelated deaths $[7,10]$, almost $(99 \%)$ of which occurred in developing countries [6].

Even in the era of combination antiretroviral therapy (cART), TB infection still places a great burden on people living with HIV (PLWH) in mainland China, a developing country. As revealed in a meta-analysis including 29 studies conducted in mainland China, the overall prevalence of TB infection among PLWH was estimated to be $7.2 \%$ (range: $4.2 \%-12.3 \%$ ) and was even higher (22.8\%) in AIDS patients [11]. In another study conducted among hospitalized patients with HIV infection in China, most AIDS-related deaths were due to TB infection [3]. Under such circumstances, knowledge of the survival and risk factors affecting mortality in HIVinfected patients with PTB would provide important insights for the clinical management of this population, which has yet to be described in the current Chinese context. Hence, we present this study to assess the survival outcome and identify the risk factors for mortality in a retrospective cohort containing 359 HIV-infected subjects with pulmonary tuberculosis (PTB) in Shanghai, China, among whom 49 cases also presented with extrapulmonary tuberculosis.

\section{Methods}

\section{Study setting and participants}

This study was retrospectively conducted among patients with HIV infection admitted to Shanghai Public Health Clinical Center (SPHCC) for medical care from January 2011 to December 2015. SPHCC is a tertiary hospital affiliated with Fudan University and is the only designated medical institution providing HIV/AIDS care for PLWH in Shanghai. Presently, more than 6000 HIVinfected individuals in Shanghai are being regularly followed up at SPHCC. In 2016, more than 1400 HIVinfected patients were admitted to SPHCC for AIDS or non-AIDS-related illnesses.

The inclusion criteria were as follows: (1) individuals older than 15 years with laboratory-confirmed HIV infection; (2) patients diagnosed with PTB based on the clinical, radiological and laboratory findings; and (3) patients diagnosed with PTB who underwent anti-TB treatment immediately. The diagnosis criteria of PTB cases in this study were in compliance with the national guidelines on the management of $\mathrm{TB}$ infection in China [12]. For laboratory-confirmed PTB cases, one of the following three conditions should be met: (1) 2 positive sputum smears by microscopy; (2) 1 positive sputum smear and 1 positive sputum culture; and (3) 1 positive sputum smear with typical features of active TB infection on chest radiological imaging [12]. For the clinical diagnosis of PTB, one 
of the four following conditions should be met after three negative sputum smears: (1) clinical symptoms, such as cough, hemoptysis and fever with typical features of active TB infection on chest radiological imaging; (2) typical findings of active TB infection on chest radiological imaging, with strongly positive results of the purified protein derivative (PPD) skin test; (3) typical findings of active TB infection on chest radiological imaging and pathological changes of TB infection in extrapulmonary tissues; and (4) suspicious cases were followed up or given diagnostic anti-TB treatment for three weeks, and other pulmonary diseases were excluded [12].

\section{Study design}

This study was a retrospective cohort study. The eligible cases had been followed up regularly since the PTB diagnosis, and the closing date for follow-up was set at $\mathrm{Au}$ gust 31, 2016. If the participants were lost to follow-up, which was defined as cases that could not be traced before the closing date, their last visit was considered, and they were further removed from subsequent follow-up. Additionally, cases that were lost to follow-up 1 month after the PTB diagnosis were excluded from the survival analysis.

First, the demographics and clinical features of the enrolled HIV and PTB co-infected patients were observed and compared between subgroups of survival and death cases. Additionally, for the primary interest of this study, the survival outcome was measured in this cohort. Furthermore, the potential risk factors associated with the mortality of HIV-infected patients with PTB were identified in this study, and the survival differences were analyzed between subjects with or without specific risk factors.

The institutional review board of SPHCC approved this study. Considering that this study was retrospective, noninterventional and anonymous, the Ethics Committee of SPHCC authorized this study without written informed consent from the participants.

\section{Data collection}

All data were retrieved by reviewing the medical records in the electronic database of the hospital information system at SPHCC. The standardized data collection tool was utilized to extract demographic characteristics, clinical symptoms, medical comorbidities besides PTB, results of laboratory and radiological examination, timing of the PTB/HIV diagnosis and treatment. The duration of the follow-up was calculated as the time from the PTB diagnosis until the time of death, last visit or close date.

\section{Statistical analysis}

Statistical analysis was performed using SPSS for Windows (version 19.0; IBM Corp, Armonk, NY). The mean
$( \pm S D)$, median (interquartile range, IQR) and frequency (\%) were used to describe the patients' characteristics in each group. The Chi-squared test was used to compare categorical variables, and group comparisons of quantitative variables were performed with the parametric (analysis of variance) or nonparametric (Mann-Whitney $U$ test) method depending on the distribution of the variable. The probability of survival after TB diagnosis was estimated by the Kaplan-Meier method. Univariate and multivariate Cox proportional hazards models were used to determine the risk factors affecting mortality by adjusting for confounding factors, in which the hazard ratio (HR) and its $95 \%$ confidence interval $(C I)$ were estimated, and all factors with statistical significance in univariate analysis were further included in the multivariate analysis. The survival differences between patients with and without specific risk factors were tested by the Kaplan-Meier method and log-rank test. Statistical significance was set at $P<0.05$ (two-tailed test).

\section{Results \\ Demographic, clinical and laboratory characteristics}

A total of 4914 HIV-infected cases were admitted to SPHCC between January 2011 and December 2015, and 359 of these patients who met the inclusion criteria were identified in the database of the hospital information system. The patients' demographic, clinical and laboratory profiles were described, as shown in Table 1. Most of these patients were male $(325 / 359,90.53 \%)$, and the median age was 39 years (IQR: $31-52$ years). At the time of PTB diagnosis, the patients' median $\mathrm{CD} 4^{+} \mathrm{T}$ cell count was extremely low, at $51 / \mathrm{mm}^{3}$ (IQR: $23-116 / \mathrm{mm}^{3}$ ), and only a few patients $(98 / 359,27.30 \%)$ were on cART.

\section{Survival analysis}

Although 26 patients were lost to follow-up 1 month after the diagnosis of PTB, 333 cases were included in the survival analysis, with a median follow-up duration of 27 months (IQR: 13-43 months) (Fig. 1), and this included 9 cases that were lost to follow-up and excluded before the closing date (median follow-up duration: 28 months; IQR: 12-36 months). During the follow-up period, 53 patients died, with an overall mortality rate of $15.92 \%$. The cumulative survival rates at 6,12 and 24 months were $87.39 \%, 85.56 \%$ and $84.31 \%$, respectively, as shown in Fig. 2, and most deaths occurred within 6 months after the PTB diagnosis (41/53, $77.36 \%)$. The clinical and demographic profiles were compared between the death and survival cases. The death cases were characterized by older age $(P<0.001)$, a lower $\mathrm{CD}_{4}^{+} \mathrm{T}$ cell count $(P<0.001)$, a lower rate of cART administration $(P=0.029)$, being more prone to diagnosis delay $(P<0.001)$, complication with bacterial pneumonia $(P<0.001)$ and clinical manifestations of 
Table 1 Demographics and clinical characteristics of HIV-infected patients with PTB

\begin{tabular}{|c|c|c|c|c|}
\hline & $\begin{array}{l}\text { Overall } \\
N=359\end{array}$ & $\begin{array}{l}\text { Survivals } \\
N=280\end{array}$ & $\begin{array}{l}\text { Deaths } \\
N=53\end{array}$ & $P$ value \\
\hline Age, Years, median (IQR) & $39(31,52)$ & $39(29,48)$ & $49(35,63)$ & $<0.001$ \\
\hline Male gender $N(\%)$ & $325(90.53 \%)$ & $254(90.71 \%)$ & 48 (90.57\%) & 1.000 \\
\hline On cART N (\%) & 98 (27.30\%) & 83 (29.64\%) & $8(15.09 \%)$ & 0.029 \\
\hline Diagnostic delay ${ }^{\mathrm{a}} N(\%)$ & $153(42.60 \%)$ & $106(37.86 \%)$ & $36(67.92 \%)$ & $<0.001$ \\
\hline Extrapulmonary Involvement & 49 (13.65\%) & 35 (12.50\%) & $12(22.64 \%)$ & 0.052 \\
\hline \multicolumn{5}{|l|}{ Clinical symptoms } \\
\hline Fever $\left(>39^{\circ} \mathrm{C}\right) \mathrm{N}(\%)$ & $263(73.26 \%)$ & 207 (73.93\%) & $32(60.38 \%)$ & 0.044 \\
\hline Cough N (\%) & $181(50.42 \%)$ & $144(51.43 \%)$ & $28(52.83 \%)$ & 0.851 \\
\hline Expectoration $N(\%)$ & $82(22.84 \%)$ & 61 (21.79\%) & 17 (32.08\%) & 0.105 \\
\hline Anorexia N (\%) & $81(22.56 \%)$ & 60 (21.45\%) & $13(24.53 \%)$ & 0.617 \\
\hline Dyspnea N (\%) & 69 (19.22\%) & 49 (17.50\%) & $16(30.19 \%)$ & 0.033 \\
\hline \multicolumn{5}{|l|}{ Complications } \\
\hline Bacterial pneumonia N (\%) & $32(8.91 \%)$ & $18(6.43 \%)$ & $14(26.42 \%)$ & $<0.001$ \\
\hline HBV/HCV co-infection N (\%) & $25(6.96 \%)$ & $19(6.79 \%)$ & $6(11.32 \%)$ & 0.387 \\
\hline Syphilis N (\%) & $33(9.19 \%)$ & $30(10.71 \%)$ & $1(1.89 \%)$ & 0.077 \\
\hline Diabetes N (\%) & $14(3.90 \%)$ & $11(3.93 \%)$ & $2(3.77 \%)$ & 1.000 \\
\hline Hypertension N (\%) & $12(3.345 \%)$ & 9 (3.21\%) & $2(3.77 \%)$ & 1.000 \\
\hline \multicolumn{5}{|l|}{ Laboratory examination } \\
\hline Sputum smear positive N (\%) & $156(43.45 \%)$ & $126(45.00 \%)$ & $21(39.62 \%)$ & 0.470 \\
\hline Sputum culture positive N (\%) & $180(50.14 \%)$ & $141(50.36 \%)$ & $23(43.40 \%)$ & 0.353 \\
\hline T-spot. TB test positive $N(\%)$ & $227(63.23 \%)$ & $181(64.64 \%)$ & $30(56.60 \%)$ & 0.265 \\
\hline HIV RNA Ig copies/ml median (IQR) & $5.17(3.91,5.66)$ & $5.14(3.83,5.65)$ & $5.32(4.61,5.79)$ & 0.354 \\
\hline $\mathrm{CD}^{+}{ }^{+} \mathrm{T}$ cell/ $/ \mathrm{mm}^{3}$ median (IQR) & $51(23116)$ & $55(27$ 122) & $24.5(10,86)$ & 0.001 \\
\hline \multicolumn{5}{|l|}{ Manifestation of lung $C T$ scan } \\
\hline Extensive pulmonary lesion ${ }^{\mathrm{b}} \mathrm{N}(\%)$ & $218(60.72 \%)$ & $160(57.14 \%)$ & $41(77.36 \%)$ & 0.006 \\
\hline Pulmonary cavity N (\%) & $36(10.03 \%)$ & $25(8.93 \%)$ & $9(16.98 \%)$ & 0.076 \\
\hline Pulmonary atelectasis $N(\%)$ & $31(8.64 \%)$ & $20(7.14 \%)$ & $9(16.98 \%)$ & 0.039 \\
\hline
\end{tabular}

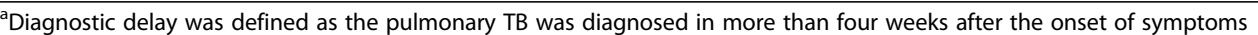

${ }^{\mathrm{b}}$ Extensive pulmonary lesion was defined as TB lesions involved more than 3 pulmonary lobes by chest CT scan

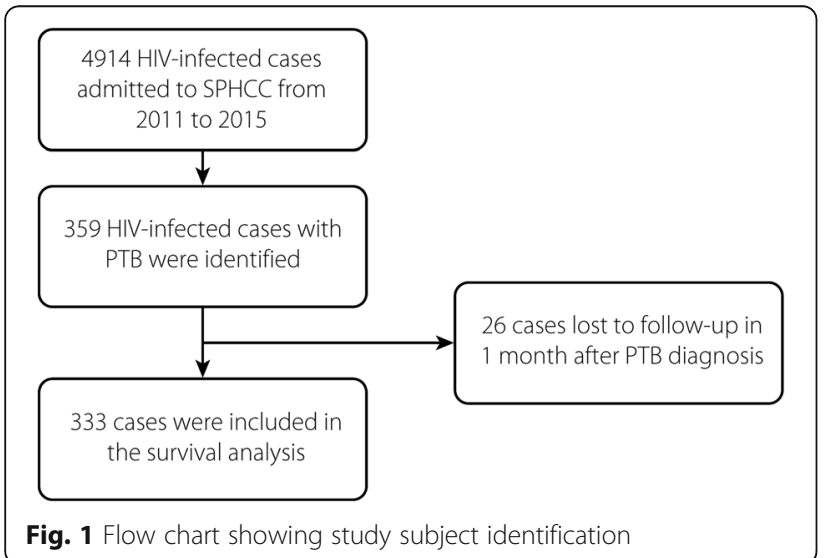

Fig. 1 Flow chart showing study subject identification dyspnea $(P=0.033)$, a reduced presence of high fever $(P=$ $0.044)$, more extensive lesions $(P=0.006)$ and pulmonary atelectasis $(P=0.039)$ shown on chest CT (Table 1$)$.

\section{Risk factors affecting survival outcome}

The variables listed in Table 2 were included in the Cox proportional hazards model to assess potential risk factors for mortality. After conducting univariate (UV) and multivariable $(\mathrm{MV})$ analyses, older age ( $>60$ years) (UV: HR: 3.31, 95\% CI: 1.80-6.10; MV: HR: 3.18, 95\% CI: 1.66-6.10), a diagnosis delay (UV: HR: $3.05,95 \%$ CI: 1.71-5.44; MV: HR: 2.60, 95\% CI: 1.42-4.78), the absence of high fever (UV: HR: 0.56; 95\% CI: 0.32-0.97; MV: HR: 0.54, 95\% CI: 0.30-0.96), complication with bacterial pneumonia (UV: HR: 4.07, 95\% CI: 2.21-7.52; MV: HR: 2.64, 95\% CI: 1.30-5.35), a CD $4^{+} \mathrm{T}$ cell count less than $50 / \mathrm{mm}^{3}$ (UV: HR: 2.70, 95\% CI: 1.48-4.90; 


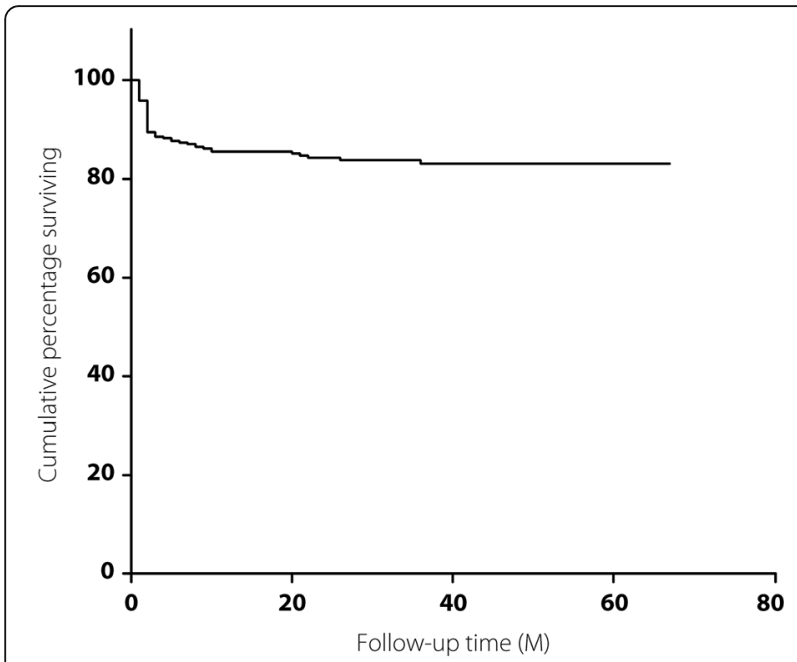

Fig. 2 Cumulative survival rate among HIV-infected patients with PTB
MV: HR: 2.38, 95\% CI: 1.27-4.43) and pulmonary atelectasis (UV: HR: 2.29, 95\% CI: 1.12-4.70; MV: HR: 2.20, 95\% CI: 1.05-4.60) shown on chest CT scan were identified as independent risk factors contributing to poor survival in these patients (Table 2). As depicted by Kaplan-Meier curves and tested by the log-rank tests, all these factors were significantly associated with decreased cumulative survival rates (Fig. 3).

Among the 217 patients who initiated cART after starting anti-TB treatment, the timing of cART initiation was associated with the survival outcome $\left(\chi^{2}=7.03, P=\right.$ 0.030), as shown in Fig. 4. Compared with patients who initiated CART within 4 weeks after beginning anti-TB treatment (Table 3), those who began cART later (more than 8 weeks after starting anti-TB treatment) had a worse survival outcome (OR: 4.33, 95\% CI: 1.22-15.36). Additionally, we found that the initiation of cART within 4-8 weeks after starting anti-TB treatment was associated with the fewest deaths (Table 3), but the difference did not reach statistical significance compared with patients initiating cART within 4 weeks after starting anti-TB treatment $(P=0.257)$.

Table 2 Risk factors associated with the mortality of HIV infected patients with PTB ${ }^{a}$

\begin{tabular}{|c|c|c|c|c|}
\hline \multirow[t]{2}{*}{ Risk factor } & \multicolumn{2}{|c|}{ Univariate analysis } & \multicolumn{2}{|c|}{ Multivariate analysis } \\
\hline & $\mathrm{HR}^{\mathrm{b}}(95 \% \mathrm{Cl})$ & $P$ value & $\mathrm{HR}^{\mathrm{b}}(95 \% \mathrm{Cl})$ & $P$ value \\
\hline Age $>60$ & $3.31(1.80-6.10)$ & $<0.001$ & $3.18(1.66-6.10)$ & 0.001 \\
\hline Male gender & $0.97(0.39-2.43)$ & 0.942 & & \\
\hline Not on CART & $2.17(1.03-4.61)$ & 0.043 & $1.48(0.67-3.25)$ & 0.332 \\
\hline Diagnosis delay & $3.05(1.71-5.44)$ & $<0.001$ & $2.60(1.42-4.78)$ & 0.002 \\
\hline \multicolumn{5}{|l|}{ Clinical symptoms } \\
\hline Fever $\left(>39^{\circ} \mathrm{C}\right)$ & $0.56(0.32-0.97)$ & 0.037 & $0.54(0.30-0.96)$ & 0.037 \\
\hline Cough & $1.05(0.61-1.81)$ & 0.850 & & \\
\hline Expectoration & $1.58(0.89-2.81)$ & 0.122 & & \\
\hline Anorexia & $1.14(0.61-2.12)$ & 0.690 & & \\
\hline Dyspnea & $1.88(1.04-3.37)$ & 0.036 & $1.03(0.53-1.97)$ & 0.941 \\
\hline Extrapulmonary Involvement & $1.83(0.96-3.48)$ & 0.066 & & \\
\hline $\mathrm{CD}^{+} \mathrm{T}$ cell count $<50$ cells $/ \mathrm{mm}^{3}$ & $2.70(1.48-4.90)$ & 0.001 & $2.38(1.27-4.43)$ & 0.007 \\
\hline \multicolumn{5}{|l|}{ Comorbidities } \\
\hline Bacterial pneumonia & $4.07(2.21-7.52)$ & $<0.001$ & $2.64(1.30-5.35)$ & 0.007 \\
\hline $\mathrm{HBV} / \mathrm{HCV}$ co-infection & $1.57(0.67-3.68)$ & 0.298 & & \\
\hline Syphilis & $0.18(0.03-1.32)$ & 0.093 & & \\
\hline Diabetes & $0.96(0.23-3.92)$ & 0.949 & & \\
\hline Hypertension & $1.13(0.27-4.62)$ & 0.871 & & \\
\hline \multicolumn{5}{|l|}{ Manifestation of lung $C T$ scan } \\
\hline Extensive pulmonary lesion & $2.39(1.26-4.55)$ & 0.008 & $1.76(0.90-3.44)$ & 0.100 \\
\hline Pulmonary cavity & $2.00(0.98-4.10)$ & 0.058 & & \\
\hline Pulmonary atelectasis & $2.29(1.12-4.70)$ & 0.023 & $2.20(1.05-4.60)$ & 0.037 \\
\hline
\end{tabular}

${ }^{\mathrm{a} S t a t i s t i c a l ~ a n a l y s i s ~ w a s ~ p e r f o r m e d ~ b y ~ t h e ~ C o x ~ p r o p o r t i o n a l-h a z a r d s ~ m o d e l ~}$

${ }^{\mathrm{b}} \mathrm{HR}$ indicated relative mortality risk for cases with the specific risk factor referred to cases without the corresponding risk factor 

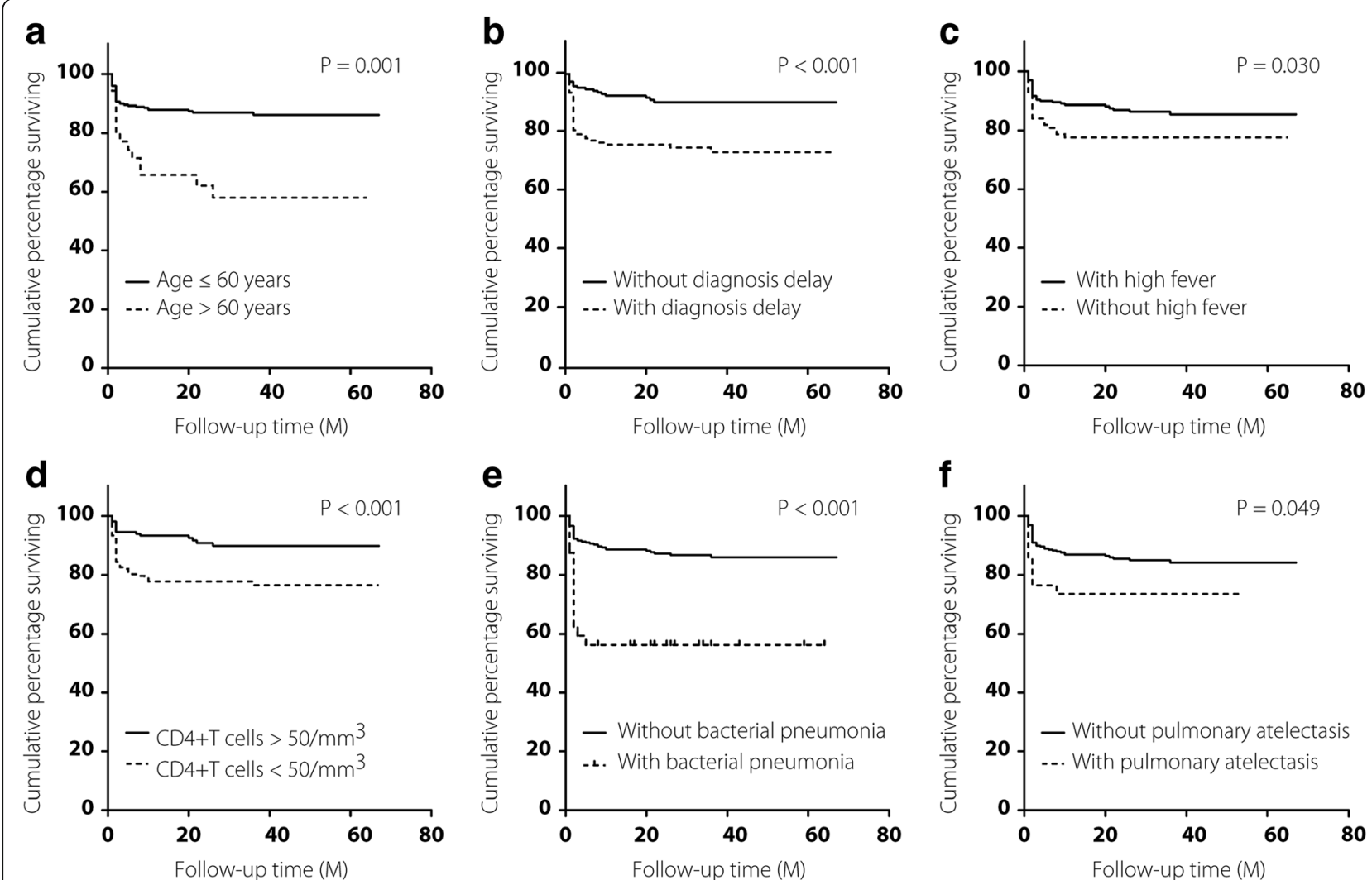

Fig. 3 Kaplan-Meier curves comparing the outcomes affected by risk factors ( $\mathbf{a}$, age $>60$ years; $\mathbf{b}$, diagnosis delay; $\mathbf{c}$, high fever; $\mathbf{d}, C D 4^{+} T$ cell count $<50 / \mathrm{mm}^{3}$; e, bacterial pneumonia; $\mathbf{f}$, pulmonary atelectasis)

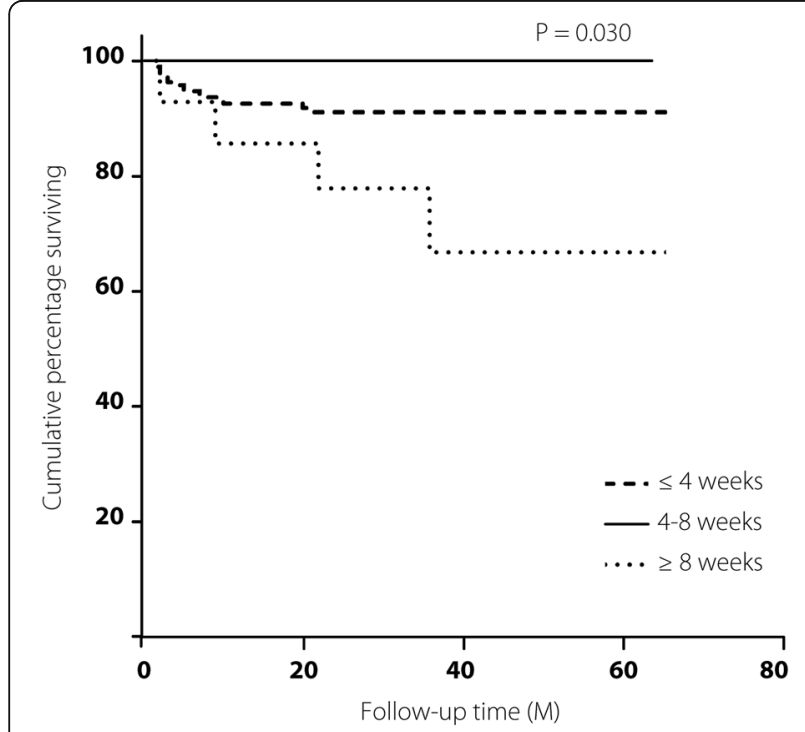

Fig. 4 Kaplan-Meier curves comparing the outcomes affected by the timing of CART initiation after starting anti-TB treatment

\section{Discussion}

In China and other developing countries, TB is the most common and life-threatening opportunistic infection in HIV-infected patients $[3,4,13]$. Our study revealed the clinical features and survival outcomes of patients coinfected with HIV and PTB. Furthermore, the potential risk factors impacting mortality were evaluated. We also found that the timing of cART initiation could affect the survival outcome in cART-naïve patients undergoing anti-TB treatment.

In this study, most of the HIV-infected patients with PTB presented with severe immunodeficiency $\left(\mathrm{CD} 4^{+} \mathrm{T}\right.$ cell count $<50 / \mathrm{mm}^{3}$ ). Additionally, at the time of the

Table 3 Survival differences among patients with different timing of CART initiation after staring anti-TB treatment ${ }^{a}$

\begin{tabular}{llll}
\hline $\begin{array}{l}\text { Timing of cART initiation } \\
\text { since starting anti-TB }\end{array}$ & Mortality rate & OR $(95 \%$ Cl $)$ & $P$ value \\
treatment & & & \\
\hline$\leq 4$ weeks & $8.47 \%(16 / 189)$ & 1 & \\
$4-8$ weeks & $0 \%(0 / 14)$ & NA $^{b}$ & 0.257 \\
$\geq 8$ weeks & $28.57 \%(4 / 14)$ & $4.33(1.22-15.36)$ & 0.015
\end{tabular}

aStatistical analysis was performed by the chi-square test

bDue to the value of variable is zero, OR could not be calculated 
PTB diagnosis, fewer than $30 \%$ of patients in this cohort had been on cART. These findings correspond with previously reported data demonstrating the close relationship between TB activation and the immunosuppressive state of the host [4, 14-16]. As in the general population, most individuals infected with Mycobacterium tuberculosis latently do not develop active $\mathrm{TB}$ infection, but individuals co-infected with HIV do [17]. HIVinduced immunosuppression presenting as the loss of $\mathrm{CD}^{+}{ }^{+} \mathrm{T}$ cells in the host's peripheral blood, lymphoid tissues, and mucosa has been regarded as the most significant risk factor for primary infection and reactivation of TB [17]. Additionally, in a meta-analysis, cART administration was strongly associated with a reduced risk of TB activation [18], indicating that cART could be the most important measure to control TB activation in HIVinfected individuals by restoring the host's immune function [19]. Hence, our findings imply that enforcing the timely initiation of cART is required to reduce the TB burden among HIV-infected populations in the current context in China.

During the median 26 months of follow-up, the overall survival rate in this cohort was comparable to that reported in recent studies of HIV/TB co-infected patients from other developing countries [4, 20-22]. While this study was conducted during the cART era, an advanced immunosuppression state and lower rate of cART administration were still identified as characteristics of death case. Furthermore, the host's $\mathrm{CD}^{+}{ }^{+} \mathrm{T}$ cell count had an independent impact on the prognosis of AIDS patients with PTB. Additionally, in other studies, the introduction of cART could drastically reduce the mortality of HIV and TB co-infected patients by effectively suppressing the replication of HIV and concomitantly raising the peripheral $\mathrm{CD}_{4}^{+} \mathrm{T}$ cell count [22-24]. As recommended in the WHO management guideline for HIV and TB co-infection, cART should be administered as soon as possible after the initiation of anti-TB treatment (within 8 weeks) without consideration of the CD4 ${ }^{+} \mathrm{T}$ cell count [25]. Consistently, in the survival analysis for patients who initiated cART after starting anti-TB treatment, our findings revealed that the later initiation of cART (more than 8 weeks after starting anti-TB treatment) could increase the risk of mortality. However, our analysis also indicated that the death rate among patients who initiated cART within 4-8 weeks after starting anti-TB treatment was lower than that in patients initiating cART within 4 weeks, although this difference did not reach statistical significance. Considering that most patients in this cohort showed an extremely low profile of the $\mathrm{CD} 4^{+} \mathrm{T}$ cell count when diagnosed with $\mathrm{PTB}$, rapid $\mathrm{CD}^{+} \mathrm{T}$ cell restoration induced by cART could lead to the phenomenon known as immune reconstitution inflammatory syndrome (IRIS), which could affect the prognosis of HIV/TB co-infection patients [17, 23]. Based on previous findings, it was suggested that the initiation of cART should be delayed in HIV and TB coinfected patients with $\mathrm{CD} 4^{+} \mathrm{T}$ cell counts $<100$ cells $/ \mathrm{mm}^{3}$ [23, 26, 27]. Additionally, for HIV and TB co-infected patients with CD4 T-cell counts $>200$ cells $/ \mathrm{mm}^{3}$, the most recent evidence even supported that cART initiation could be delayed until completion of the 6 months of anti-TB treatment to avoid adverse events [28]. While the optimized timing of cART initiation after starting anti-TB therapy has not been determined, the results of our study indicate that the initiation of cART within 4-8 weeks after the start of anti-TB treatment could improve the survival outcome, especially for patients with low $\mathrm{CD}^{+} \mathrm{T}$ cell counts. The findings deserve further prospective investigations in the future.

The early diagnosis and immediate initiation of anti$\mathrm{TB}$ treatment are essential for $\mathrm{TB}$ management, while HIV infection has been identified as an important factor associated with a delayed diagnosis of TB infection in a systemic review [29]. Consistently, in this study, a diagnosis delay was common, as more than $40 \%$ subjects were diagnosed with PTB later than 4 weeks after disease onset. Several reasons lead to the delay of the PTB diagnosis in HIV-infected patients, including extensive involvement of the lower lung lobes, atypical chest radiographic findings, low concentrations of bacteria in the sputum and frequent extrapulmonary involvement [30]. The role of delay in the diagnosis of TB is significant for both disease progression and patient outcome [29] and has been reconfirmed in our study among HIV/ PTB co-infected individuals. Currently, there are numerous novel technologies to improve the diagnosis of TB in patients with HIV infection. In a randomized trial conducted in areas with a high prevalence of $\mathrm{TB}$ and HIV infection, use of the Xpert method to diagnose TB infection in primary care clinics increased the number of confirmed TB cases and reduced the time to treatment initiation among HIV-infected patients [31]. Future studies to investigate the role of these newly developed TB diagnostic methods to improve the outcome of AIDS patients with PTB are expected.

Similar to that reported in previous studies conducted in HIV- or non-HIV-infected patients with PTB, the prognosis was worse among elderly patients ( $\geq 60$ years old) than among younger individuals in this cohort, possibly attributed to a lower body weight, coexisting medical diseases and extensive radiographic involvement in elderly patients [21, 32]. Additionally, other risk factors, such as the absence of high fever, manifestation of dyspnea, complication of bacterial pneumonia and pulmonary atelectasis shown on chest CT scan, were found to be associated with poor survival in this cohort. Future studies to optimize the management of these clinical 
challenges in HIV/TB co-infection patients should be conducted.

Admittedly, several limitations were endowed in this study. First, it was an observational and retrospective study; recall bias from medical record review could not be eliminated. Meanwhile, this study did not include non-HIVinfected patients with PTB as a proper control group, which could strengthen the conclusions of our study. Additionally, the cases lost to follow-up in this cohort could be a bias to more precisely estimate the survival outcome. We also note that the findings revealed in this study do not fully represent the overall view of the outcome for HIV and PTB co-infected patients of China, especially in other regions with different socioeconomic and medical resource statuses. Finally, while the survival outcomes and risk factors affecting mortality identified in this study provide insight into improving clinical management and promoting further investigations of the HIV/PTB co-infection population in China, it is important to note that these findings need to be reappraised, especially in future interventional or prospective observational studies.

\section{Conclusions}

This study revealed the survival outcome of HIV-infected patients with PTB in China, which was comparable to that reported in other developing regions. Currently, HIVinfected patients complicated with PTB in China are still characterized by a depressed immunological profile and low rates of cART administration, indicating that promoting the timely administration of and adherence to cART remain the primary measures to reduce the TB burden in HIV-infected subjects under such circumstances. Additionally, for clinical management, our findings identified that several factors, including older age, a diagnosis delay, complication with bacterial pneumonia, serious disease manifestations and the timing of cART initiation, could be challenges to improving the survival outcome in HIV/PTB co-infected populations. To explore optimization strategies for HIV/PTB management, further investigations based upon these findings should be conducted.

\section{Additional file}

Additional file 1: Multilingual abstracts in the five official working languages of the United Nations. (PDF $210 \mathrm{~kb}$ )

\section{Abbreviations \\ AIDS: Acquired immunodeficiency syndrome; CART: Combination antiretroviral therapy; Cl: Confidence interval; HIV: Human immunodeficiency virus; HR: Hazard ratio; IQR: Interquartile range; OR: Odds ratio; PLWH: People living with HIV infection; PTB: Pulmonary tuberculosis; SPHCC: Shanghai Public Health Clinical Center; TB: Tuberculosis; WHO: World Health Organization}

\section{Acknowledgements}

We would like to thank the staff of the Department of Infectious Diseases at Shanghai Public Health Clinical Center for their contribution to this work.

\section{Funding}

This study was supported by the National Natural Science Foundation of China (NSFC No. 81571977 and No. 31500697) and Medical Science Support Program by Shanghai Science and Technology Committee (No. 16411960400).

Availability of data and materials

Study data are available at the internal database of SPHCC. Please contact Mr. Yongjia Ji at 15111300004@fudan.edu.cn.

\section{Authors' contributions}

H-ZL, Y-JJ and P-PL conceived and designed the study. J-JS, J-YY, JC, T-KQ, ZYW, WS, YT, LL, R-FZ and Y-ZS collected the data and interpreted the results. Y$\mathrm{JJ}$ and J-YS wrote the paper. All authors approved the final version of this work.

\section{Ethics approval and consent to participate}

The Ethics Committee of SPHCC approved this study. Considering that this study was retrospective, noninterventional and anonymous, the Ethics Committee of

SPHCC authorized this study without written informed consent from participants.

\section{Consent for publication}

Not applicable.

\section{Competing interests}

The authors declare that they have no competing interests.

\section{Author details}

${ }^{1}$ Department of Infectious Disease, Shanghai Public Health Clinical Center, Fudan University, No. 2901 Cao Lang Rd, Jinshan District, Shanghai 201508, China. ${ }^{2}$ Department of Infectious Disease, Huashan Hospital Affiliated to Fudan University, Shanghai 200040, China. ${ }^{3}$ Department of Internal Medicine, Shanghai Medical College, Fudan University, Shanghai 200032, China.

Received: 5 July 2017 Accepted: 12 March 2018

Published online: 24 March 2018

\section{References}

1. Godfrey-Faussett P, Maher D, Mukadi YD, Nunn P, Perriëns J, Raviglione M How human immunodeficiency virus voluntary testing can contribute to tuberculosis control. Bull World Health Organ. 2002;80:939-45.

2. World Health Organization. Global Tuberculosis Report 2016. Geneva: World Health Organization; 2016. http://apps.who.int/medicinedocs/en/d/ Js23098en/. Accessed 12 June 2017

3. Ji Y, Wang Z, Shen J, Chen J, Yang J, Qi T, et al. Trends and characteristics of all-cause mortality among HIV-infected inpatients during the HAART era (2006-2015) in Shanghai, China. Biosci Trends. 2017;11(1):62-8. https://doi. org/10.5582/bst.2016.01195.

4. Sharma S, Soneja M, Prasad K, Ranjan S. Clinical profile \& predictors of poor outcome of adult HIV-tuberculosis patients in a tertiary care Centre in North India. Indian J Med Res. 2014;139(1):154-60.

5. Lawn SD, Zumla Al. Tuberculosis. Lancet. 2011;378(9785):57-72. https://doi. org/10.1016/s0140-6736(10)62173-3.

6. Pawlowski A, Jansson M, Skold M, Rottenberg ME, Kallenius G. Tuberculosis and HIV co-infection. PLoS Pathog. 2012;8(2):e1002464. https://doi.org/10. 1371/journal.ppat.1002464.

7. Getahun H, Gunneberg C, Granich R, Nunn P. HIV infection-associated tuberculosis: the epidemiology and the response. Clin Infect Dis. 2010; 50(Suppl 3):S201-7. https://doi.org/10.1086/651492.

8. Modjarrad K, Vermund SH. Effect of treating co-infections on HIV-1 viral load: a systematic review. Lancet Infect Dis. 2010;10(7):455-63. https://doi. org/10.1016/S1473-3099(10)70093-1.

9. Giri P, Deshpande J, Phalke D. Prevalence of pulmonary tuberculosis among HIV positive patients attending antiretroviral therapy clinic. N Am J Med Sci. 2013;5(6):367-70. https://doi.org/10.4103/1947-2714.114169.

10. Corbett EL, Watt CJ, Walker N, Maher D, Williams BG, Raviglione MC, et al. The growing burden of tuberculosis: global trends and interactions with the HIV epidemic. Arch Intern Med. 2003;163(9):1009-21.

11. Gao L, Zhou F, Li X, Jin Q. HIV/TB co-infection in mainland China: a meta-analysis. PLoS One. 2010;5(5):e10736. https://doi.org/10.1371/journal.pone.0010736.

12. Chinese Center for Disease Control and Prevention. National TB control program implementation guide in China (2008). Beijing: Peking Union Medical College Press; 2009. 
13. Xiao J, Gao G, Li Y, Zhang W, Tian Y, Huang Y, et al. Spectrums of opportunistic infections and malignancies in HIV-infected patients in tertiary care hospital, China. PLoS One. 2013;8(10):e75915. https://doi.org/10.1371/journal.pone.0075915.

14. Bhaskaran U. Clinico epidemiological profile of HIV - TB coinfection among PLHIV in coastal south India. BMC Infect Dis. 2014;14(Suppl 2):P32. https:// doi.org/10.1186/1471-2334-14-s2-p32.

15. Manosuthi W, Chottanapand S, Thongyen S, Chaovavanich A, Sungkanuparph S. Survival rate and risk factors of mortality among HIV/ tuberculosis-coinfected patients with and without antiretroviral therapy. J Acquir Immune Defic Syndr. 2006;43(1):42-6. https://doi.org/10.1097/01.qai. 0000230521.86964 .86$.

16. Rao P, Chawla K, Shenoy VP, Mukhopadhyay C. Characterization of TB-HIV co infected cases of Udupi district in coastal Karnataka. BMC Infect Dis, 2014;14(Suppl 3):P52. https://doi.org/10.1186/1471-2334-14-s3-p52.

17. Bruchfeld J, Correia-Neves M, Kallenius G. Tuberculosis and HIV coinfection. Cold Spring Harb Perspect Med. 2015;5(7):a017871. https://doi.org/10.1101/ cshperspect.a017871.

18. Suthar AB, Lawn SD, del Amo J, Getahun H, Dye C, Sculier D, et al. Antiretroviral therapy for prevention of tuberculosis in adults with HIV: a systematic review and meta-analysis. PLoS Med. 2012;9(7):e1001270. https:// doi.org/10.1371/journal.pmed.1001270.

19. Lawn SD, Bekker L-G, Wood R. How effectively does HAART restore immune responses to Mycobacterium tuberculosis? Implications for tuberculosis control. AIDS. 2005;19(11):1113-24.

20. Agarwal U, Kumar A, Behera D. Profile of HIV associated tuberculosis at a tertiary institute in setting of free anti-retroviral therapy. J Assoc Physicians India. 2009;57:685-90.

21. Ambadekar NN, Zodpey SP, Soni RN, Lanjewar SP. Treatment outcome and its attributes in TB-HIV co-infected patients registered under revised national TB control program: a retrospective cohort analysis. Public Health. 2015; 129(6):783-9. https://doi.org/10.1016/j.puhe.2015.03.006.

22. Vijay S, Kumar P, Chauhan LS, Rao SV, Vaidyanathan P. Treatment outcome and mortality at one and half year follow-up of HIV infected TB patients under TB control programme in a district of South India. PLoS One. 2011: 6(7):e21008. https://doi.org/10.1371/journal.pone.0021008.

23. Dheda K, Lampe FC, Johnson MA, Lipman MC. Outcome of HIV-associated tuberculosis in the era of highly active antiretroviral therapy. J Infect Dis. 2004:190(9):1670-6. https://doi.org/10.1086/424676.

24. Hakim J, Musiime V, Szubert AJ, Mallewa J, Siika A, Agutu C, et al. Enhanced prophylaxis plus antiretroviral therapy for advanced HIV infection in Africa. N Engl J Med. 2017;377(3):233-45. https://doi.org/10.1056/NEJMoa1615822.

25. World Health Organization. Antiretroviral therapy for HIV infection in adults and adolescents: recommendations for a public health approach. 2010 revision. Geneva: World Health Organization; 2010.

26. World Health Organization. Guidelines for treatment of tuberculosis. Geneva: World Health Organization; 2010. http://www.who.int/tb/publications/2010/ 9789241547833/en/. Accessed 12 Oct 2017

27. Abdool Karim S, Naidoo K, Grobler A, Padayatchi N, Nair G, Bamber S, et al. Initiating ART during TB treatment significantly increases survival: results of a randomized controlled clinical trial in TB/HIV-co-infected patients in South Africa. In: 16th conference on retroviruses and opportunistic infections: 2009; 2009. p. 8-11.

28. Mfinanga SG, Kirenga BJ, Chanda DM, Mutayoba B, Mthiyane T, Yimer G, et al. Early versus delayed initiation of highly active antiretroviral therapy for HIVpositive adults with newly diagnosed pulmonary tuberculosis (TB-HAART): a prospective, international, randomised, placebo-controlled trial. Lancet Infect Dis. 2014;14(7):563-71. https://doi.org/10.1016/S1473-3099(14)70733-9.

29. Storla DG, Yimer S, Bjune GA. A systematic review of delay in the diagnosis and treatment of tuberculosis. BMC Public Health. 2008;8(1):15. https://doi. org/10.1186/1471-2458-8-15.

30. Perkins MD, Cunningham J. Facing the crisis: improving the diagnosis of tuberculosis in the HIV era. J Infect Dis. 2007;196(Suppl 1):S15-27. https:// doi.org/10.1086/518656.

31. Cox HS, Mbhele S, Mohess N, Whitelaw A, Muller O, Zemanay W, et al. Impact of Xpert MTB/RIF for TB diagnosis in a primary care clinic with high TB and HIV prevalence in South Africa: a pragmatic randomised trial. PLoS Med. 2014;11(11):e1001760. https://doi.org/10.1371/journal.pmed.1001760.

32. Wang CS, Chen HC, Yang CJ, Wang WY, Chong IW, Hwang JJ, et al. The impact of age on the demographic, clinical, radiographic characteristics and treatment outcomes of pulmonary tuberculosis patients in Taiwan. Infection. 2008;36(4):335-40. https://doi.org/10.1007/s15010-008-7199-8.

\section{Submit your next manuscript to BioMed Central and we will help you at every step:}

- We accept pre-submission inquiries

- Our selector tool helps you to find the most relevant journal

- We provide round the clock customer support

- Convenient online submission

- Thorough peer review

- Inclusion in PubMed and all major indexing services

- Maximum visibility for your research

Submit your manuscript at www.biomedcentral.com/submit
Biomed Central 